\title{
A POLARIZAÇÃO DOS CORPOS DESEJANTES
}

\author{
Guaraci da Silva Lopes Martins[1]
}

\begin{abstract}
Resumo
O presente artigo resulta do interesse na investigação sobre as relações de poder associadas à subjetividade dos corpos. Para tanto, desenvolveu-se uma análise com base no filme Meninos não Choram sob a direção de Kimberly Pierce, obra artística que contribui para o processo de questionamento de discursos que tendem à manutenção de hierarquias socialmente construídas e manifestadas em diferentes formas de opressão contra o feminino. Ainda que seja alvo de discriminação, de exclusão, de evasão escolar, esta temática permanece à margem das discussões no ambiente escolar. Considera-se que ao contrariar normas e regras que transitam pela via dos discursos, tal como Brandon/Tenna, protagonista do referido filme, muitos estudantes também desestabilizam limites de fronteira entre o masculino/ feminino. Assim, o filme analisado é um estímulo à reflexão sobre as identificações consideradas arbitrárias acerca da heteronormatividade e sobre a urgente necessidade de estratégias políticas e pedagógicas comprometidas com novas abordagens sobre os processos socioculturais envolvidos na construção das identidades.
\end{abstract}

Palavras-chave: educação; arte; identificações.

\begin{abstract}
This article is the result of an investigation on bodies subjectivity linked to power relations. For that, a study of this picture Boys don't cry, by Kimberly Pierce has been developed. In fact, that film is a major source for some specific speeches concerning social hierarchy maintenance, built and also shown in different forms of oppression against the female gender. Since this gender keeps on being discriminated, as well as being put aside, and somehow doesn't fulfill all school years, this theme is not supposed to be focused in conversations at school. It is to be considered that this motion picture character, Brandon/Tenna can be compared to a number of students who are not able to deal well with male/female gender boards. Thus, this film turns out to be an utter point for reflexion on arbitrary thoughts towards heteronormativity. Besides, Boys don't cry invites people to think over urgent political and pedagogic needs due to new approaches on social cultural processes linked to the construction of identities.
\end{abstract}

Keywords: school education; art; identifications.

\section{INTRODUÇÃo}

Desde o ano de 2009 esta pesquisadora participa do Grupo de Estudos e Pesquisas em Relações de Gênero e Tecnologia - GETEC do PPGTE/UTFPR, grupo este que contribui para o aprofundamento da reflexão de todas/todos as/os envolvidas/os sobre as relações de

№: 21-22 Ano: 13 jan/fev/mar/abr/mai/jun 2011 
poder associadas à subjetividade dos corpos. Em um desses encontros quinzenais que acontecem ao longo do ano, a discussão sobre este tema foi desenvolvida com base no filme Meninos não Choram sob a direção de Kimberly Peirce. Seguindo a organização estabelecida pelo grupo, naquele momento específico o debate se iniciou com a fala desta pesquisadora, a partir da análise prévia com determinados apontamentos sobre o referido filme. Esta experiência culminou com o interesse da mesma na elaboração do presente artigo com o intuito de contribuir no processo de questionamento de discursos que tendem à manutenção de hierarquias socialmente construídas e manifestadas em diferentes formas de opressão, de violência contra o feminino em diversas instituições sociais, incluindo-se o espaço escolar.

Assim sendo, acredita-se que ao contrariar conceitos, normas e regras que transitam pela via dos discursos, num ato eminentemente político, a/o protagonista do referido filme Brandon/Tenna desestabiliza conceitos demarcadores dos limites de fronteira entre o masculino/feminino. O filme aqui analisado, é um convite para a reflexão sobre as identificações consideradas arbitrárias à heteronormatividade, e também sobre a urgente necessidade de estratégias políticas e pedagógicas comprometidas com novas abordagens sobre os processos socioculturais envolvidos na construção das identidades.

Baseado em uma história verídica, logo no início do filme Os Meninos não Choram dirigido por Kimberly Peirce, a personagem Brandon/Teena anuncia a subjetividade corporificada que se constrói em um movimento em direção ao "outro". Assim, com a sua própria imagem, ela/ele convida os espectadores ao questionamento dos limites produzidos no campo da heterossexualização naturalizada dos corpos. Para Judith Butler (2003), quando se age e se deseja reproduzir o homem ou a mulher de verdade, espera-se que cada ato seja reconhecido como aquele que nos posiciona legitimamente na ordem de gênero, fazendo-se funcionar um conjunto de verdades que se acredita estarem fundamentadas na natureza. De fato, as expectativas por parte do outro estão intimamente relacionadas às idealizações dos gêneros: verdades que definem os comportamentos, os desejos e os pensamentos apropriados para homens e para mulheres.

A relação das personagens centrais em Meninos não choram abala a pequena comunidade na medida em que contraria a lei de perpetuação da espécie que rege as relações sexuais e reifica as noções binárias de gênero. Quer-se explicitar que o filme leva para o espaço da cena a relação afetivossexual de duas pessoas que rompem com a rígida fronteira estabelecida aos corpos, o que vem a desestabilizar o sistema de troca sobre o qual a regra da exogamia se legitima.

Diante daquele relacionamento, as próprias mulheres, constituídas como tais dentro das normas da heteronormatividade compulsória demonstram a sua indignação e o seu repúdio contra aquela relação considerada como anormal, antinatural. Nesse sentido, o filme denuncia o status quo de controle moral e social ainda presente na atualidade. Um homem ou uma mulher "de verdade" deverá ser necessariamente heterossexual, sob o risco de ser exilada/exilado das relações sociais, punida/punido com a morte, a exemplo de Meninos não choram. Ainda se parte de uma noção de corpo como alvo passivo sobre o qual se inscreve um conjunto de significados culturais e se reforça a ideia de uma essência naturalmente masculina ou feminina, inscrita na subjetividade. Em Berenice Bento (2006) lê-se que o corpo é um texto socialmente construído, um arquivo da história do processo de produção-reprodução sexual que ganha inteligibilidade por intermédio da heterossexualidade condicionada e circunscrita pelas convenções históricas.

Gradativamente, o corpo se molda às convenções que foram social e culturalmente estabelecidas para o gênero, marcadas pelo binarismo homem/mulher e determinantes também na forma de as pessoas manifestarem os seus sentimentos, emoções e desejos: "Nascer homem ou nascer mulher, em nossa sociedade, cria uma identidade em oposição à

№:21-22 Ano: 13 jan/fev/mar/abr/mai/jun 2011 
do sexo que não é o seu (o sexo oposto), distanciando-se dele e negando-o." (AUAD, 2003, p.57). Esta é a ordem a ser obedecida no sistema binário dos gêneros produtor e reprodutor da ideia: a de que o gênero reflete o sexo e todas as outras esferas constitutivas dos sujeitos estão associadas à naturalização dos corpos.

Por outro lado, para Guacira Lopes Louro, "na medida em que várias identificações - gays, lésbicas, queers, bissexuais, transexuais, travestis - emergem publicamente, elas também acabam por evidenciar, de forma muito concreta, a instabilidade e a fluidez das identidades sexuais". (2001, p. 31). De fato, na vida em sociedade, assim como no mundo da ficção especialmente por meio das linguagens artísticas, é possível constatar o amplo leque de manifestações que gradativamente evidenciam o caráter inventado, cultural e instável das identificações.

Tal como a/o personagem Brandon/Tenna, determinados sujeitos que também se constroem no espaço da resistência às normas regulatórias, "afetam, assim, não só seus próprios destinos, mas certezas, cânones e convenções culturais." (LOURO, 2008, p. 2425). Ao se identificar no terreno da masculinidade, esta personagem contraria as formas socialmente estabelecidas ao sujeito "desejante" e assume a condição de "desviante" da norma e isso interrompe a linha de continuidade e de coerência que se supõe natural entre corpo, sexualidade e gênero. Com efeito, uma ação política por excelência, mas "nas atuais condições, um ato que ainda pode cobrar o alto preço da estigmatização". (LOURO, 2001, p.31). O diretor Kimberly Peirce expõe ao espectador a homofobia levada às últimas consequências com a morte da personagem Brandon/Tenna, vítima de variadas formas de violência física, moral e psicológica ao longo de todo o desenrolar desta obra cinematográfica.

\section{O ESPAÇO ESCOLAR NO PROCESSO DE MUDANÇA}

A escola faz parte integrante da sociedade em que se vive e muitas vezes ela reforça e reproduz códigos de condutas circunscritas a modelos de vigilância e de controle, produzindo também o indivíduo da sociedade disciplinar. Contudo, a instituição escolar é um espaço ideal para oferecer condições necessárias para que os estudantes desenvolvam o exercício de questionamentos de pressupostos pautados no senso comum. Este que oferece condições para que as pessoas operem sobre a realidade circundante, ao mesmo tempo em que as orienta na busca do sentido da existência. Entretanto, de acordo com as autoras abaixo:

O senso comum não é refletido: impõe-se sem críticas ao grupo social. Por ser um conjunto de concepções fragmentadas, muitas vezes incoerentes, condiciona a aceitação mecânica e passiva de valores não-questionados. Com frequência, o senso comum se torna fonte de preconceitos, quando desconsidera opiniões divergentes. (ARANHA e MARTINS, 1992, p. 56)

Os signos possuem uma característica dinâmica; portanto, considerar o seu conteúdo único implica a eliminação das contradições sociais pela imposição de um só sentido para a realidade. Os processos políticos e culturais implicados na reprodução de ideologias e nas práticas sociais opressivas em todos os aspectos da organização escolar e da vida diária da sala de aula merecem o urgente envolvimento das/dos docentes em suas ações docentes. Tal implicação precisa estar pondo em xeque as diferentes formas de feminilidade e masculinidade constituídas socialmente, e nesta esteira, a naturalização e a superioridade

№: 21-22 Ano: 13 jan/fev/mar/abr/mai/jun 2011 
da heterossexualidade.

Importa esclarecer que, por mais de uma década esta pesquisadora exerceu a função docente no Ensino Médio no Colégio Estadual do Paraná onde ministrou a disciplina de Artes norteada pela área específica de formação dela. Dessa forma, nas aulas de teatro teve-se a oportunidade de observar que os papéis sociais e padrões de comportamento estabelecidos pela sociedade marcadamente heteronormativa são levados para o espaço da cena pela grande maioria das/dos adolescentes.

Acrescente-se que desde o ingresso na FAP esta estudiosa ministra a disciplina curricular obrigatória - Estágio Supervisionado - no terceiro ano do Curso de Licenciatura em Teatro quando a/o aluna(o) desenvolve o seu estágio em instituições de ensino regular nos anos finais do Ensino Fundamental e Médio. Os depoimentos obtidos ao longo do estágio realizado pelas(os) alunas(os) em processo de formação e também a supervisão empreendida no campo de atuação deles/as constatam a urgência da adoção de estratégias pedagógicas voltadas para a igualdade de direitos na escola, no interior da ordem social existente. Mais uma vez foi possível observar a marcante presença de estereótipos em torno do corpo naturalizado e reproduzido nas atividades teatrais desenvolvidas pelos estudantes do Ensino Básico. Lembro que as diferenças existem e é a partir delas que se é posicionado e se posiciona.

É na minha disponibilidade permanente à vida a que me entrego de corpo inteiro, pensar crítico, emoção, curiosidade, desejo, que vou aprendendo a ser eu mesmo em minha relação com o contrário de mim. E quanto mais me dou à experiência de lidar sem medo, sem preconceito, com as diferenças, tanto melhor me conheço e construo meu perfil. (FREIRE, 2004, p.134)

Contudo, o reconhecimento das diferenças muitas vezes é utilizado para criar desigualdade; principalmente nas sociedades ocidentais que tendem a transformar o que é diferente em desigual; então, estabelecem uma hierarquia de poder entre os diferentes, apresentando uns como superiores e outros como inferiores. Essa é uma lógica política que tende à dominação de uns sobre outros, e que muitas vezes tende a ferir a cidadania plena dos sujeitos. A regulação de conduta também se inscreve nos discursos do currículo, que autoriza ou desautoriza, legitima ou deslegitima, inclui ou exclui.

$\mathrm{Na}$ perspectiva dos Estudos Culturais, as/os professoras/es definem o seu terreno político porque oferecem às/aos estudantes discursos alternativos e práticas sociais críticas, cujos interesses estão em dissonância com o papel hegemônico da escola e com a sociedade que a mesma apoia. Entende-se que a escola é um espaço que precisa caminhar "de mãos dadas" com todos os processos que se inclinam a uma sociedade mais justa e igualitária, especialmente porque os pressupostos de universalidade, responsáveis pela prescrição de um único modelo familiar, matrimonial e amoroso permanecem na sociedade contemporânea, marcada por fortes reações, geralmente pautada em bases religiosas, autodefinidas como defensoras da família verdadeira, legítima, sagrada e natural.

É importante salientar que o reconhecimento social de experiências de multiplicidade afetivossexuais e de novas modalidades familiares está efetivamente ocorrendo. Em sua pesquisa sobre as novas famílias, Luiz Mello (2005) refere-se à variedade histórica que evidencia as dificuldades de construção de conceitos gerais e unívocos de família e de casamento. $\mathrm{O}$ autor discute o número cada vez maior de gays e lésbicas que

№: 21-22 Ano: $13 \quad$ jan/fev/mar/abr/mai/jun 2011 
decidem de variadas formas tornar pública a sua orientação sexual, na tentativa de superação da discriminação: "não omitindo de seus parentes, amigos, vizinhos e colegas de trabalho, a existência de um cônjuge do mesmo sexo em suas vidas, numa atitude claramente política". (MELLO, 2005, p.21).

Nesse contexto, as lutas políticas dos homossexuais no que se refere ao reconhecimento de suas relações afetivossexuais estáveis como de ordem familiar, é o resultado de questionamentos e transformações importantes para a dissociação do exercício da sexualidade das demais esferas do casamento e da reprodução. Essas lutas evidenciam a compreensão da família e dos cônjuges como construções socioculturais dinâmicas e mutáveis. Concordando com Mello (2005), na transcendência dos limites das fronteiras, por meio de suas vivências amorosas e sexuais, muitos sujeitos acabam por desafiar os fundamentos básicos da normatividade social.

É oportuno mencionar um importante movimento, cuja meta é estimular e garantir medidas legislativas, administrativas e organizacionais, para que em todo sistema brasileiro de ensino seja assegurada a inclusão do nome social de travestis e transexuais nos diários escolares. Em uma de suas recentes reportagens, o jornal "Gazeta do Povo" de maior circulação no estado do Paraná, divulgou uma nota na primeira página com a seguinte manchete: "Transexual ganha na Justiça o direito a mudar de nome sem cirurgia de sexo".

Na reportagem, o leitor é informado ter o Judiciário paranaense tomado uma decisão inédita no Estado, no sentido de autorizar a mudança do nome masculino de uma transexual feminina, sem que esta tenha realizado a intervenção médica para a readequação de sexo. No corpo da matéria, a advogada da transexual, C.A., declara: "Eu convivi com ela e presenciei situações constrangedoras. Teve de abandonar os estudos pelo preconceito que sofria (...)" (GAZETA DO POVO, 08/01/2009). Na mesma página, a manchete "Entidades querem que escola use o nome social", trata sobre situações discriminatórias contra as/os transexuais, tal como texto abaixo selecionado:

O preconceito e o constrangimento são algumas das causas que levam transexuais a abandonarem a escola. Muitos não completam sequer o ensino fundamental e na fase adulta acabam sem profissão definida. (GAZETA DO POVO, 08/01/09, p. 8)

Na mesma matéria encontra-se o depoimento de Keila Simpsom, atual presidente da Articulação Nacional dos Travestis, Transexuais e Transgêneros (ANTRA), por meio da qual ela nos esclarece: "A evasão escolar em razão do preconceito é uma realidade. Eles não estudam porque não querem, mas porque as escolas se fecharam”. O jornal acrescenta ainda que:

As associações não dispõem de estatísticas referentes ao universo de travestis e transexuais em fase escolar. Mas, segundo Keila, há estimativas indicando que $90 \%$ dos travestis e transexuais estão na prostituição, enquanto um percentual de apenas $3 \%$ a $5 \%$ estuda. (Gazeta do Povo, 08/01/09, p. 8)

Para Mary Garcia Castro Castro et al (2004), a discriminação contra homossexuais, além de ser abertamente assumida, em particular por jovens alunos, é valorizada entre eles, “o que sugere um padrão de masculinidade por estereótipos e medo ao estranho próximo, o 
outro, que não deve ser confundido consigo" (Ibid., p. 280). É possível afirmar, voltando-se ao filme Meninos não choram que Brandon/Teena carrega consigo um inaceitável comportamento de conduta imoral e favorece aos que o rodeiam a oportunidade do massacre: ele/ela feriu os padrões previamente estabelecidos pela convenção social. Para as pessoas que o/a perseguem ele/ela estaria contrariando a natureza; por isso, deve ser destruído/ destruída.

Ora, a violação do direito de ser e de estar neste mundo, tal como aconteceu com Brandon/ Teena permanece muito presente no contexto social dos dias atuais. Observa-se que, enquanto aqueles/aquelas que buscam seus/suas iguais biológicos/biológicas como parceiros afetivossexuais, permanecerem sob o estigma doença-pecado-crime - o monopólio do desejo permanecerá restrito à relação homem-mulher. Nessa perspectiva, obras de arte como Meninos não Choram são de extrema relevância na medida em que desafiam generalizações e contribuem para a reflexão das/ dos espectadoras/espectadores sobre questões pertinentes à ambiguidade, multiplicidade e fluidez das identificações de gênero e sexualidade.

\section{O QUEER NO CENÁRIO EDUCACIONAL CONTEMPORÂNEO}

Ao estender a hipótese da construção social para o domínio da sexualidade, a teoria queer problematiza a identidade sexual considerada normal: a heterossexualidade compulsória da sociedade. Para Nádia Perez Pino (2007), essa teoria se interessa pelos gestos ou modelos analíticos que evidenciam as incoerências da suposta relação estável e revelam que a heterossexualidade não é natural, mas é o efeito do poder, do controle e da regulação social.

Acrescente-se que a teoria queer não se resume na afirmação da identidade homossexual, mas contribui para o desenvolvimento de novas perspectivas, na medida em que ela aponta para a multiplicidade das subjetivações e das práticas, o que contraria conceitos pautados na coerência e na estabilização de identidades. Ela contribui para o questionamento de verdades que definem os comportamentos, os desejos e os pensamentos apropriados para homens e para mulheres.

Tal como a teoria queer, quando norteada por uma metodologia de análise e compreensão do conhecimento e das identificações sexuais, a pedagogia queer o possibilita a problematização das classificações e dos enquadramentos que impõem limites à concepção de gênero e de sexualidade. Para Louro (2008) uma pedagogia e um currículo queer possibilitaria o questionamento da polarização heterossexual/homossexual, pondo em xeque a naturalização e o caráter superior produzido em torno da heterossexualidade.

De fato, a pedagogia queer propicia o olhar mais ampliado sobre a fluidez das identidades, sugerindo ainda "novas formas de pensar a cultura, o conhecimento, o poder e a educação" (Ibid., p. 47). Saliente-se que o amplo campo teórico existente hoje em torno do sexo, gênero e sexualidade se mantém inexplorado no ambiente escolar. Mesmo em se tratando dos temas transversais que integram os Parâmetros Curriculares Nacionais, esta temática é direcionada principalmente para a prevenção da gravidez entre as/os adolescentes e das doenças sexualmente transmissíveis com enfoque mais direcionado para a AIDS.

\section{CONSIDERAÇÕES FINAIS}

Na mesma medida em que os discursos sobre a sexualidade estão se modificando e se multiplicando, também os mecanismos de resistências pautadas em ideias conservadoras se desdobram com novos tipos de intervenção social e políticas; elas buscam, com efeito, a preservação da concepção fortemente polarizada dos gêneros. Os efeitos de doutrinas naturalistas e conservadoras culminam na violação de direitos humanos praticada contra

№: 21-22 Ano: 13 jan/fev/mar/abr/mai/jun 2011 $44 \quad$ Cadernos de Gênero e Tecnologia 
determinados sujeitos que interrompem a linha de continuidade e de coerência que se supõe natural entre sexo, gênero e sexualidade.

No filme, Meninos não Choram, a trágica morte da protagonista é apenas um exemplo dentre tantos outros atos de violência perversamente cometidos contra determinados sujeitos na cena da vida cotidiana. Frequentemente os meios de comunicação deste país estampam manchetes relacionadas a atos desumanos, incluindo agressões e assassinatos contra pessoas em função de sua orientação sexual. Contudo, não se pode perder a capacidade de indignação diante de situações que violam os princípios básicos de uma vida cidadã. Entende-se que pensar em Direitos Humanos em pleno século XXI significa refletir sobre os aspectos éticos, socioeconômicos, culturais, normativos e de relação com o poder que se apresentam em nosso cotidiano. Significa pensar nas formas de opressão vivenciadas por segmentos historicamente ausentes do circuito de direitos e sobre as demandas no campo da diversidade.

Convive-se com uma pluralidade de interpretações e de construções de subjetividade com significados múltiplos, ao contrário do que alguns discursos apontam para afirmar as identidades monolíticas e coerentes. Acredita-se que os primeiros passos para se lidar com as questões de gênero se encontram em propostas que permitam a compreensão ampliada em termos de pluralidades e de diversidades. Este processo de mudança necessita partir de uma epistemologia capaz de contribuir para a subversão de esquemas que impedem as pessoas de se expressarem ou vivenciarem suas relações, seja dentro ou fora dos padrões da heterossexualidade.

A escola precisa articular-se com as novas necessidades, com as novas situações e reformular as diretrizes de seus objetivos, visando a resultados além das competências cognitivas e intelectuais para atingir também o espaço das competências morais e afetivas. Assim, é imprescindível que as teorias e práticas educacionais forneçam as condições necessárias para que cenas de violência vivenciadas por Brandon/Teena sejam questionadas visando a minimização das injustiças e das relações sociais de desigualdade.

As configurações de gênero devem se fazer presente no currículo escolar de todos os níveis de educação como uma área legítima de conhecimento no processo de formação do sujeito. Nesta perspectiva, a partir das primeiras etapas da vida acadêmica, a escola possibilitaria uma melhor relação da criança com as diferenças de gênero, com os tabus relativos ao corpo. Cabe o investimento em processos de ensino e aprendizagem potencialmente críticos e transformadores, para que as/os estudantes desenvolvam a oportunidade de aprender os conhecimentos e as habilidades necessárias para a vida em uma autêntica democracia.

É possível afirmar que a instituição educacional pode viabilizar o questionamento da concepção fortemente polarizada dos gêneros. O desafio está no entendimento dos/das professores/as de que as identidades são cambiantes, contestáveis e discursivamente construídas, para que possam estender essa discussão para o espaço da sala de aula. $\mathrm{Na}$ medida em que o estudo sobre a construção e as práticas identitárias devem incorporar-se no currículo das escolas é fundamental que essa temática se faça presente no processo de formação inicial e continuada do professorado.

\section{NOTA}

[1] Especialista em Didática para o Curso Superior-PUC/PR; Mestre em Educação-Universidade Tuiuti do Paraná; Doutora em Artes Cênicas-UFBA; docente da Faculdade de Artes do Paraná - FAP; líder do Grupo de Pesquisa Arte, Educação e

№: 21-22 Ano: 13 jan/fev/mar/abr/mai/jun 2011 
Formação Continuada; integrante do Grupo de Estudos e Pesquisas e Relações de Gênero e Tecnologia - GETEC do PPGTE/CEFET-PR.

\section{REFERENNCIAS}

ARANHA, Maria Lúcia; MARTINS, Maria Helena Pires. Temas de filosofia. São Paulo: Moderna, 1992.

AUAD, Daniela. Feminismo: que história é essa? Rio de Janeiro: DP\&A, 2003.

BENTO. Berenice. A reinvenção do corpo: sexualidade e gênero na experiência transexual. Rio de Janeiro: Garamond, 2006.

BOREK, Vinicius Direitos Humanos: Transexual pode trocar de nome sem fazer cirurgia. Curitiba: Gazeta do Povo, 08 jan. 2009, p.8.

BUTLER, Judith. Problemas de Gênero: feminismo e subversão da identidade. Trad. Renato Aguiar. Rio de Janeiro: Civilização Brasileira, 2003.

CASTRO, Mary Garcia et al. Juventudes e Sexualidade. Brasília: UNESCO, 2004.

FREIRE, Paulo. Pedagogia da autonomia: saberes necessários à prática educativa. 30 ed. São Paulo: Paz e Terra, 2004.

LOURO, Guacira Lopes. Pedagogias da sexualidade. In: O Corpo educado: pedagogias da sexualidade. (org.) .et al. Belo Horizonte: autêntica, 2001

. Um corpo estranho. Ensaios sobre sexualidade e a teoria queer. Belo Horizonte: Autêntica, 2008.

MELLO, Luiz. Novas familias. Conjugalidade homossexual no Brasil contemporâneo. Rio de Janeiro: Garamond, 2005. PINO, Nádia Perez. A teoria queer e os intersex: experiências invisíveis de corpos des-feitos. In: Cadernos Pagu.

Campinas, n. 28, p. 149-174, Jan./Jun. 2007. ISSN 0104-8333. Disponível em: http://www.scielo.br/pdf/cpa/n28/08.pdf. Acesso em: 13 abr. 2011.

SILVA, Tomaz Tadeu. Documentos de Identidade: uma introdução às teorias do currículo. 9 reimp. Belo Horizonte: Autêntica, 2005 
№: 21-22 Ano: 13 jan/fev/mar/abr/mai/jun 2011

Cadernos de Gênero e Tecnologia 